\title{
Medical Image of the Week: Cheyne-Stokes Respiration
}

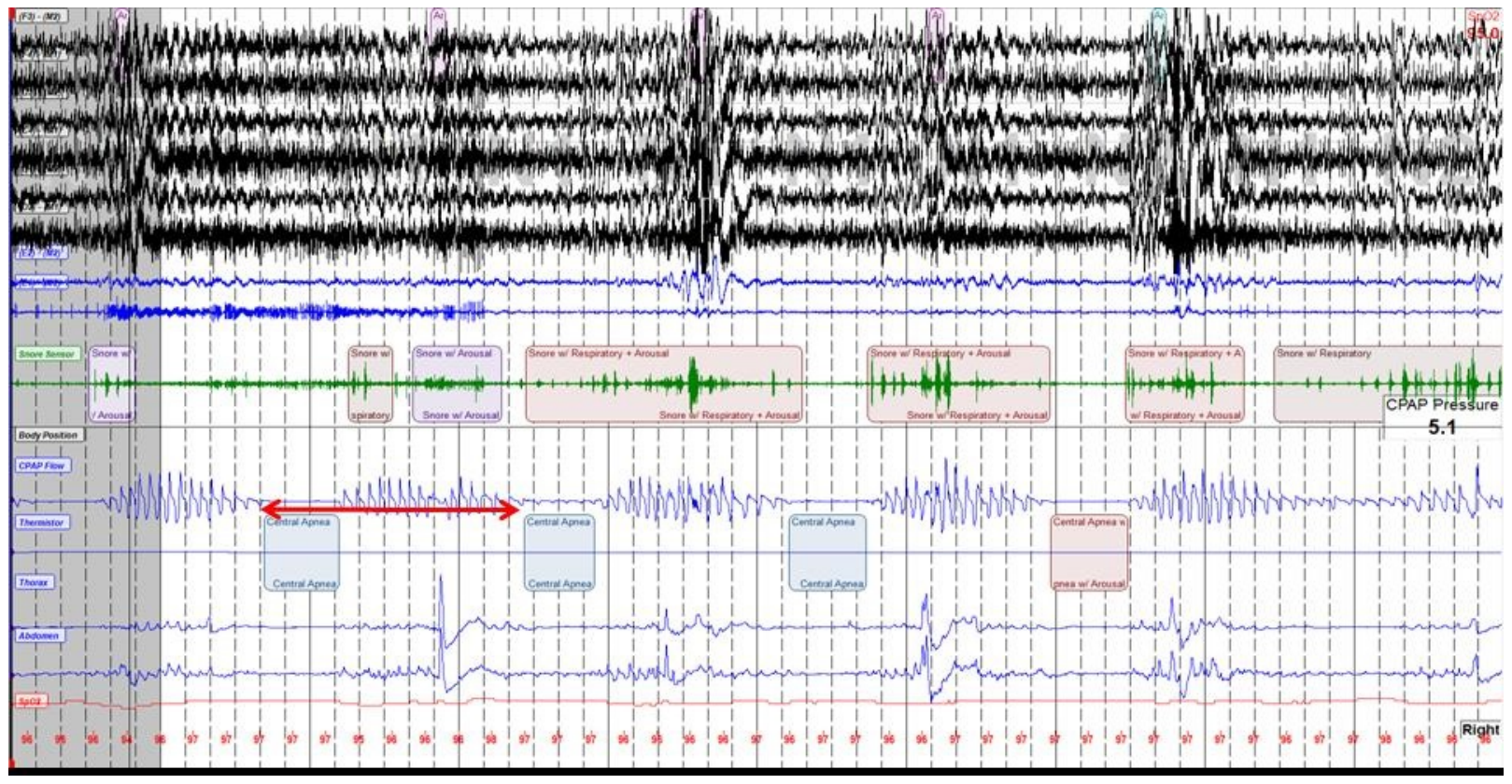

Figure 1. Cheyne-Stokes Breathing pattern seen. The red arrow indicates the cycle time which is defined as the duration of the central apnea (or hypopnea) + the duration of a respiratory phase.

A 62 year-old male with a past medical history congestive heart failure, chronic obstructive pulmonary disease, and obesity with a body mass index of $38.02 \mathrm{~kg} / \mathrm{m}^{2}$ underwent an overnight polysomnogram for clinical suspicion for obstructive sleep apnea. He was found to have a periodic breathing as seen in the image above.

Cheyne-stokes respiration (CSR) is a type of periodic breathing characterized by crescendo-decrescendo pattern of respiration separated by central sleep apneas (CSA) or hypopneas (1). CSR-CSA may be seen in up to $15-37 \%$ of systolic heart failure patients $(2,3)$. A longer cycle length, usually between $45-90$ seconds, as well as the waxing and waning breathing pattern differentiate CSR from other forms of cyclic central apnea. CSA leads to chronically increased sympathetic activity and exerts multiple deleterious effects on the failing heart (2). The presence of CSR has been associated with higher mortality and rapid deterioration in cardiac function (4).

Jared Bartell and Safal Shetty, MD University of Arizona Medical Center Tucson, AZ 


\section{References}

1. Berry RB, Budhiraja R, Gottlieb DJ, Gozal D, Iber C, Kapur VK, Marcus CL, Mehra R, Parthasarathy S, Quan SF, Redline S, Strohl KP, Davidson Ward SL, Tangredi MM; American Academy of Sleep Medicine. Rules for scoring respiratory events in sleep: update of the 2007 AASM Manual for the Scoring of Sleep and Associated Events. Deliberations of the Sleep Apnea Definitions Task Force of the American Academy of Sleep Medicine. J Clin Sleep Med. 2012;8(5):597-619. [CrossRef] [PubMed]

2. Yumino D, Bradley TD. Central sleep apnea and Cheyne-Stokes respiration. Proc Am Thorac Soc. 2008;5(2):226-36. [CrossRef] [PubMed]

3. Garcia-Touchard A, Somers VK, Olson LJ, Caples SM. Central sleep apnea: implications for congestive heart failure. Chest. 2008;133(6):1495-504. [CrossRef] [PubMed]

4. Hanly PJ, Zuberi-Khokhar NS. Increased mortality associated with Cheyne-Stokes respiration in patients with congestive heart failure. Am J Respir Crit Care Med. 1996;153(1):272-6. [CrossRef] [PubMed] 